\title{
UM SAPATEIRO E SUA BIBLIOTECA: O FAZER-SE DE UM COMUNISTA NA CIDADE DE PARANAGUÁ ${ }^{1}$
}

\author{
Thiago Ernesto Possiede da Silva ${ }^{2}$
}

- Enviado em 29/01/2016

- Aprovado em 15/02/2016

\begin{abstract}
RESUMO
O objetivo deste artigo é discutir o processo de formação da militância comunista em Paranaguá, litoral do Paraná, entre 1935 a 1964. Nosso ponto de partida é a trajetória do sapateiro Antônio Araújo Rocha, militante do Partido Comunista em Paranaguá, atuante tanto na estrutura interna do partido como nas relações com os trabalhadores da cidade. Analisamos as mobilizações dos trabalhadores relacionadas à militância comunista, bem como suas organizações, conflitos internos e externos e seu processo de formação durante o recorte temporal que adotamos. Como fio condutor, o sapateiro Antônio Araújo Rocha é destacado nesta pesquisa como principal motor para o desenvolvimento do estudo, ora apresentado com maior destaque, ora aparecendo como coadjuvante nas experiências e práticas políticas dos trabalhadores de Paranaguá. Buscamos compreender sua formação intelectual, a partir de sua biblioteca pessoal e de suas atividades como militante comunista tendo como principal referência os estudos de Edward Palmer Thompson e sua noção de processo histórico. A pesquisa foi desenvolvida a partir de documentos levantados pela Delegacia de Ordem Política e Social - DOPS, localizados no Arquivo Público do Paraná e do acervo de livros do sapateiro Antônio Araújo Rocha, em posse de sua família, em Paranaguá.
\end{abstract}

Palavras-chave: Militância Comunista. Trabalhadores. Processo Histórico. Paranaguá.

\section{INTRODUÇÃO}

Este artigo tem o objetivo de discutir o processo de formação da militância comunista em Paranaguá entre os trabalhadores da cidade a partir da trajetória de Antônio Araújo Rocha, sapateiro e posteriormente militante do Partido Comunista. Buscaremos analisar alguns conflitos na cidade entre trabalhadores e patrões, entre os próprios militantes e entre militantes e a repressão e perseguição política do Estado, observando pontos específicos como indícios significativos da mobilização operária na busca por mais direitos sociais.

\footnotetext{
${ }^{1}$ Dissertação de mestrado em História defendida em 2014. Versão completa disponível na Biblioteca Digital da UFPR: $<\underline{\text { http://hdl.handle.net/1884/38560 }}>$

2 Doutorando do Programa de Pós-Graduação em História da Universidade Federal do Paraná e bolsista CAPES, na linha de pesquisa Intersubjetividade e Pluralidade: Reflexão e Sentimentos na História. Mestre em História pelo mesmo Programa em 2014. E-mail: thiagopossiede@gmail.com
} 
A noção de processo, discutida pelo historiador Edward Thompson, oferece-nos a possibilidade de analisar a formação da militância comunista em Paranaguá, a partir de suas atuações que podem parecer pequenos fragmentos, dispersos no tempo e no espaço, com pouca, ou nenhuma relevância, mas, se relacionados e compreendidos, a militância surge reivindicando direitos e melhores salários para os trabalhadores, propondo projetos políticos, organizando-se e organizando mobilizações e greves. Entretanto, a militância política não está desconectada de sua realidade, não é algo à parte que flutua sobre as cabeças das pessoas que se tornam militantes.

Antes de militantes, são trabalhadores, aderem à causa de um partido político e de um conjunto de ideias e símbolos políticos por inúmeras razões, sejam movidos à utopia revolucionária ou para conseguir o sustento de si e para a família. Thompson pensou a classe operária afirmando incisivamente que, "não surgiu tal como o sol numa hora determinada. Ela estava presente em seu próprio fazer-se",3, em uma relação, onde "a classe acontece quando alguns homens, como resultado de experiências comuns (herdadas ou compartilhadas), sentem e articulam a identidade de seus interesses entre si, e contra outros homens cujos interesses diferem (e geralmente se opõem) dos seus" 4 .

Uma trajetória não é uma série única e sucessiva de acontecimentos, sem vínculos para além do sujeito que é objeto da análise. Os acontecimentos biográficos que veremos definem-se, de acordo com Pierre Bourdieu, como colocações e deslocamentos no espaço social. Não podemos compreender uma trajetória sem estarmos cientes da necessidade de construir os estados que se sucedem no campo ao qual ela se desenvolveu diante do processo histórico, ou seja, saber que o sujeito manteve relações com outros agentes envolvidos ${ }^{5}$.

Considerando o espaço em que atuam os trabalhadores ligados ao partido e a trajetória de Antônio Rocha, apontamos que as experiências destes indivíduos estavam relacionadas diretamente com a conjuntura nacional e internacional, uma vez que o porto era um ponto de contato com outros centros, além de manterem contato com o acervo de Antônio Rocha que continha no momento desta pesquisa 1860 livros e da imprensa comunista que circulava pelos militantes.

\footnotetext{
${ }^{3}$ THOMPSON, Edward Palmer. A formação da classe operária inglesa: A árvore da liberdade. Trad. Denise Bottmann. Rio de Janeiro: Paz e Terra, 1987. p. 9.

${ }^{4}$ Idem. p. 10.

5 BOURDIEU, Pierre. A ilusão biográfica. In: FERREIRA, Marieta de Moraes; AMADO, Janaina. (Org.). Usos e abusos da História Oral. Rio de Janeiro: FGV, 1996.
} 


\section{COMUNISTAS NO LITORAL DO PARANÁ: EXPERIÊNCIAS E CONFLITOS}

Nosso objetivo se concentra em apresentar as incidências de comunistas na cidade de Paranaguá, a fim de destacar que é neste ambiente que o sapateiro Antônio Araújo Rocha insere-se, igualmente, identifica-se ser o circuito onde os companheiros de militância do sapateiro estão presentes. Observaremos debates entre alguns militantes, evidenciando críticas, acusações e conflitos internos, bem como a movimentação de comunistas junto aos estivadores, uma vez que muitos destes estivadores são identificados pela Polícia Política como membros do PCB.

Unido à movimentação dos trabalhadores de Paranaguá, destacamos a especificidade de Antônio Araújo Rocha nessa conjuntura, apontando que sua militância, em particular, se caracteriza por não ser um estivador em uma cidade predominantemente repleta destes trabalhadores, participava das mobilizações políticas, mas, não era sindicalizado. Podemos verificar isso a partir do seu depoimento, quando é perguntado sobre como era a sua atuação política e se era sindicalizado,

Eu não participei de sindicato porque não sou sindicalizado, mas participava muito dessas [greves], paralelamente. Assim, né... Participava dessas lutas, executando as tarefas na rua, fazendo essas coisas, propaganda na rua, né. Então, quer dizer que eu não falo em nome de sindicato, porque eu não sou sindicalizado. Participo das lutas, tenho o direito. [frase incompreensível], essa é a minha contribuição, de uma pessoa que participou das lutas ${ }^{6}$.

Dessa forma, partimos de um relatório da DOPS, a respeito da infiltração de comunistas em Paranaguá, em especial no porto.

"Acabo de regressar do litoral, onde entrei em contacto diréto com os comunistas de Paranaguá e Antonina, assim como com os ferroviarios, desde a estação de Banhado até a primeira daquélas"7. 25 de novembro de 1946, o agente da Delegacia de Ordem Política e Social (DOPS) identificando-se como Louis Antoine, informa seu superior a respeito do que observou na região do litoral do Estado do Paraná, descrevendo sua infiltração entre os trabalhadores, com o objetivo de colher o máximo de informações que apontem indícios da influência das ideias comunistas e, da organização dos operários para a greve em curso. O relatório descreve com maiores detalhes, a situação na cidade de Paranaguá e apresenta alguns apontamentos acerca de Antonina:

O MOVIMENTO GREVISTA:

O movimento irrompeu na "Estiva Terrestre", de acordo com a "Estiva Maritima" e com os ferroviarios de Paranaguá, assim como com os estivadores de

\footnotetext{
${ }^{6}$ Transcrição do depoimento concedido ao Centro de Memória Sindical do Paraná, em Curitiba, 1988. p. 06.

${ }^{7}$ DEAP/DOPS. Dossiê: Delegacia de Polícia de Paranaguá. №: 584A. Topografia: 65. p. 5.
} 
Antonina. O motivo da gréve: aumento de salarios, para Cr.\$30, 00 e extraordinarios em dobro, ou seja á razão de Cr.\$ 8,00 por hóra de trabalho, além das 8 horas. Segundo declaração que ouvi de varios dos grevistas, foi dada uma trégua de 10 dias, que terminará no dia 2 de dezembro. Si dentro desse prazo não forem atendidos nas suas pretensões, irromperá o movimento, nóvamente, com apoio dos estivadores maritimos de Paranaguá e dos seus colégas de Antonina. Tais declarações ouvi de Nortenio de Tal, presidente do Sindicato de Trabalhadores Terrestres, de Armazens, de Trapiches e Café, e de José Bezerra de Vasconcellos, presidente do Sindicato dos Estivadores de Paranaguá ${ }^{8}$.

Em 23 de novembro, o delegado Palmyro de Oliveira, responsável pela Delegacia Regional de Polícia, em carta encaminhada ao Interventor Federal do Estado, Major Fernando Flores, relata que no dia 28 de outubro, o presidente do Sindicato dos Trabalhadores, chamado Nortenio Nascimento, enviou uma carta ao diretor do Departamento do Cais do Porto - Antonio Artigas pedindo o aumento dos salários, "em virtude da grande carestia da vida que atravessamos no momento", a resposta de Artigas foi negativa, destacando que "nada tinha que vêr com o Sindicato, e sim, com a Associação dos Trabalhadores Portuários, Associação éssa que, segundo consta, não existe".

No dia 5 de novembro, Nortenio Nascimento responde Artigas, convidando-o para debater o assunto em uma reunião, o que é também negado pelo referido diretor. Alguns dias depois, em 10 de novembro, Nortenio "oficiou ao Dr. Artigas, dizendo que no dia 22 do mês atual, os trabalhadores dariam a resposta do seu último oficio, o que fiséram ontem, com o seu não comparecimento ao trabalho à noite", .

Observando o primeiro trecho do relatório do agente Antoine, a respeito do Movimento Grevista, é possível perceber que há indícios da articulação entre os trabalhadores do litoral, principalmente se for considerado o contato que a linha férrea faz entre as cidades de Paranaguá e Antonina, bem como as relações marítimas, uma vez que as duas regiões são áreas portuárias, onde o fluxo de pessoas é constante, possibilitando a circulação de informações. Um terreno fértil para a organização operária.

Antoine afirma que as declarações dos trabalhadores foram apresentadas por Nortenio Nascimento e José Bezerra de Vasconcellos, o primeiro, como já mencionado, é presidente do Sindicato dos Trabalhadores Terrestres, dos Armazéns, dos Trapiches e do Café; o segundo, presidente do Sindicato dos Estivadores de Paranaguá.

\footnotetext{
${ }^{8}$ DEAP/DOPS. Dossiê: Delegacia de Polícia de Paranaguá. No: 584A. Topografia: 65. p. 5. Durante a leitura da fonte, nota-se que a escrita diferencia-se do português atual. Decidi manter a escrita original, por motivos estéticos, apresentando como a pessoa escreveu seu texto.
}

${ }^{9}$ DEAP/DOPS. Dossiê: Delegacia de Polícia de Paranaguá. №: 584A. Topografia: 65. p. 8. 
A única informação a respeito de José Bezerra de Vasconcellos, para além do relatório, aponta que é filiado ao Comitê Estadual do Partido Comunista do Brasil, em Paranaguá, a partir do mês de outubro de $1945^{10}$. Sobre Nortenio Nascimento, em uma carta provavelmente destinada ao delegado da DOPS em Curitiba, datada de 31 de março de 1948, uma pessoa identificada como "Jorge", escreve que ele é um "elemento fomentador de queixas, e descontentamentos. Foi candidato a vereador pelo P. C.” e expõe suas impressões acerca de alguns comunistas na cidade e de sua intenção de ficar próximo deles, agindo sob cautela, pois,

[...] Atualmente os elementos andam muito precatados. Eu ainda não frequentei nenhuma reunião, mais assim que o fizer, te mandarei contar o assunto ventilado na mesma. Eu tenho procurado chegar muito de manso, porque eles sempre suspeitam de gente que vai de Curitiba para Paranaguá ou Antonina, para passar temporadas.

Tem um navio do Loide, que as vezes traz jornais e correspondência do Rio para o pessoal daquí. Vou procurar saber e informarei, o que se trata.

Eu não tenho demonstrado muito interesse assim de chegada, porque o pessoal é muito espérto, e não quero nem de leve que suspeitem, que estou do outro lado.

Tenho estado em contato com elementos, mas muitos deles, (não sei se é verdade ou não), mostran-se desinteressados das atividades comunistas; outros conservam a mesma animação pelo crédo, mas estão mais desconfiados.

Vou procurar saber cérto o navio que traz propaganda, bem como o elemento que aquí a recebe e para onde a manda.

[...] Espero que isto sirva para inicio de meu trabalho, e fazer jus a promessa que fizestes; [...] Tudo pelo nosso querido Brasil, com um abraço do, Jorge ${ }^{11}$.

A partir de 1945, o Partido Comunista do Brasil entra para a legalidade, e que será logo retirada em 1947, no entanto, este curto período proporciona um aumento considerável em seu contingente, levando-nos a pensar que membros do PCB faziam-se presentes em diferentes áreas do trabalho na cidade de Paranaguá ${ }^{12}$. Neste sentido, Louis Antoine inicia seus apontamentos destacando a presença de comunistas na cidade, enfatizando a região portuária e central.

\section{MOVIMENTO COMUNISTA:}

Em Paranaguá, todo aquêle que não fôr da Policia e se disser simpático ao crédo vermelho, terá a impressão de que está numa cidade genuinamente comunista. O primeiro elemento com quem entrei em contacto, ali, foi Oswaldo Silva, funcionário da Alfandega, com exercicio na Comissão do Porto. Disse-me ele que não é fichado no P. C., porque funcionário da Comissão, encarregado de receber e transmitir mensagens e propaganda, si fosse elemento fichado, fatalmente, seria prejudicado. Apresentou-me êle, em seguida, Sebastião Moreira, destacado prócer vermelho e João Sovalski, ambos da célula de Paranaguá. O proprietário da Pensão Central, situado numa esquina, defronte ao Restaurante Cruzeiro, assim como o proprietario do Bar Pinguim, são comunistas. Em

${ }^{10}$ DEAP/DOPS. Ficha Individual de José Bezerra de Vasconcellos. No 45. 292.

${ }^{11}$ DEAP/DOPS. Dossiê: Delegacia de Polícia de Paranaguá. Nº 584C. Topografia: 65. p. 105.

${ }^{12}$ Sobre o período de legalidade do Partido Comunista do Brasil e de seu contingente nesse momento, no Estado do Paraná e na cidade de Paranaguá, iremos discutir mais adiante. 
ambos os estabelecimentos se reunem grupos comunistas, conspirando. Rodadas de cerveja ou de cachaça servem de disfarce para as reuniões.

NO PORTO:

Depois de examinada a situação no "Centro", passei-me para o Porto, acompanhado de Oswaldo. Fui visitar, Machadinho, maquinista da Estrada, vélho e conhecido comunista, atualmente licenciado da Rêde, estabelecido no Porto, com um botequim. Não o encontrei. Permanecí, então, no botequim do "seu" Antonio, visinho de Machadinho e seu compadre, também comunista. Alí é que falei com os grevistas e com estivadores maritimos. Nessa casa entravam e saiam, á cada instante, maritimos dos vapores "Caxambú" e "Farrapo", todos eles comunistas, aos quais o "seu" Antonio e Oswaldo me apresentavam como "camarada". Sempre que indagavam da missão que me levava ali, respondia: "Ando colhendo dados para um folheto de propaganda que vou escrever sobre o desenvolvimento do comunismo no Paraná." Horas depois falei com Machadinho. A sua casa é um verdadeiro "arsenal" comunista, de material de propaganda. Machadinho é, de instante em instante, procurado por ferroviarios comunistas. Repetiu-me êle as mesmas cousas que me foram ditas pelos presidente dos Sindicatos, sobre a gréve, adiantando-me que não tardará a gréve na Estrada, mesmo que seja uma pequena gréve. "Estamos, assim, nos preparando para a gréve geral e talvez para a revolução", disse êle.

$\mathrm{Na}$ casa de Machadinho vi dois cartazes. No primeiro dizia assim: "Vende-se jornais do Partido Comunista Brasileiro. Operario lê os teus jornais". No outro: "Já não devemos dar apoio a Moysés Lupion e ao P. T. B., porque ambos déram as mãos ao P. R. P., Partido Integralista". Ouvi, aliás, de todos os comunistas dali, e de vários estivadores de Antonina, que haviam chegado pelo trem de domingo, a mesma opinião. De Machadinho e de Oswaldo Silva ouvi ainda o seguinte: "Êles não querem que nossas fileiras engrossem, mas êles mesmos estão nos auxiliando. O Delegado Palmiro é um bandido! Tem dado de palmatória e metido a borracha nos operários, que, lógo em seguida entram no nosso partido. O pessoal de Limpesa Pública está vindo todo para nós. Ganham pouco, teem os vencimentos atrazados e retiram vales que um funcionário da Prefeitura desconta com 40 $\%$...".

PROVA DE ORGANIZAÇÃO:

Do Porto, já ás 8 horas da noite voltei sózinho, de ônibus. Fui jantar no Bar Pinguim, na Rua 15. Mal tomára assento em uma mesa oculta, apareceu um senhor de bôa aparencia que, encostado ao balcão pediu um cópo de vinho. A seguir tomou lugar na minha mesa, sem pedir licença. Apresentou-se como comunista, dizendo-se tio de Flavio Ribeiro, chamar-se Oscar Saldanha e ser enfermeiro militar, reformado. Está passando algum tempo em Paranaguá, foi o que disse. Da palestra que mantive com êle, e, posteriormente, com Oswaldo Silva, conclui que Oscar foi ali como emissário de Flavio e desempenha o papel de orientador daquéla gente. "O Patitucci é o chefe porque é delegado do Centro, mas nós gente de mais valor que orienta os nossos homens", disse-me Oswaldo. Dos 600 associados do Sindicato dos Maritimos e dos 300 da Estiva Terrestre, mais de 600 são filiados ao comunismo.

EM ANTONINA:

Segundo palestra que mantive com Tainhóta presidente do Sindicato da Estiva, pessoa que me fora indicada como a mais credenciada (como) para falar, soube que a célula dalí conta com uns 300 filiados, além de mais uma centena de simpatizantes. Também não darão apoio á Lupion e aos do P. T. B., e são solidários com os grevistas de Paranaguá ${ }^{13}$.

$\mathrm{O}$ agente Antoine oferece informações que, compreendidas como parte de um processo que se desenvolve no início da década de 1920 (com a fundação do PCB em 1922), apresentam-se passíveis de entendê-las no sentido da formação da militância política e da adesão dos trabalhadores ao debate político, com vistas a garantir condições de vida favoráveis à sobrevivência e, em

\footnotetext{
${ }^{13}$ DEAP/DOPS. Dossiê: Delegacia de Polícia de Paranaguá. No: 584A. Topografia: 65. pp. 5-6.
} 
medidas diversas, observar a inserção da cultura política comunista como signo mobilizador às lutas cotidianas.

Entretanto, é preciso considerar que, diante do relatório apresentado, sabemos de sua parcialidade e escrita tendenciosa, uma vez que o agente é funcionário da Polícia Política, cuja tarefa é combater aquilo que pode ser potencialmente ameaçador para a segurança nacional. Em contrapartida, a riqueza de detalhes que o relatório oferece possibilita compreender sua leitura a respeito da movimentação dos trabalhadores, identificando-os na identidade de comunistas, o que permite perscrutar ecos de um passado de militância e de resistência à repressão do Estado.

A insatisfação dos trabalhadores em relação aos seus salários se traduz em ameaça de continuar com a greve, caso suas reivindicações não sejam atendidas. A partir deste ponto, sinais da violência policial surgem quando é dito que o delegado Palmyro é responsável pela repressão, tendo "metido a borracha nos operários". E essa mesma violência é apontada como uma ligação dos operários com o PCB e do aumento dos seus membros, podendo ser um elo chave para a resistência, a junção da insatisfação salarial com certo ressentimento e ódio, em relação à violência da polícia, materializada na figura do delegado, aquele "bandido!".

Do porto ao centro de Paranaguá, o agente Louis Antoine entra em contato com vários militantes, justificando que sua presença, na região, é estritamente informativa, "colhendo dados para um folheto de propaganda que vou escrever sobre o desenvolvimento do comunismo no Paraná", certamente colheu dados de muito interesse para a Polícia Política, observando a circulação de militantes comunistas pela cidade e, entrando em contato com alguns membros do partido que desempenhavam, possivelmente, funções de divulgação da imprensa comunista, como é destacado o papel da pessoa identificada como Machadinho ${ }^{14}$, que é "de instante em instante, procurado por ferroviários comunistas", possuindo em sua casa um "verdadeiro 'arsenal' comunista, de material de propaganda".

Chegando ao Bar Pinguim, localizado no centro da cidade, com endereço à Rua XV de novembro, Antoine se aproxima de dois nomes importantes da estrutura interna do partido - o primeiro em nível estadual e o segundo em nível municipal -, via Oscar Saldanha, homem que segundo ele, "diz-se tio de Flavio Ribeiro" e que está na cidade como emissário do mesmo, para desempenhar a função de orientador "daquéla gente", e que o Patitucci "é o Chefe porque é delegado do Centro, mas nós gente de mais valor que orienta nossos homens".

O ano é de 1946, é provável considerar que a presença de Oscar Saldanha na cidade se deva ao IV Congresso do Partido Comunista do Brasil, ao qual irá mobilizar os militantes para o

\footnotetext{
${ }^{14}$ A respeito de Machadinho, não encontrei informações sobre sua atuação no partido, nem sobre o seu nome.
} 
debate em torno da Assembleia Nacional Constituinte, e terá como uma das pontas de lança o pedido de revogação da Carta de 1937, bem como a escolha de candidatos para as eleições daquele ano.

De acordo com o estudo de Márcio Mauri Kieller Gonçalves, Flavio Ribeiro fez parte dos dirigentes do Partido Comunista no Paraná, foi secretário de divulgação e propaganda entre 1945/47 e diretor do Jornal do Povo até 1949, atuando fundamentalmente na organização do partido na região norte do Paraná ${ }^{15}$. Segundo um relatório da DOPS, presente em seu dossiê, o qual oferece um histórico de sua trajetória no partido, Flavio Ribeiro fixou-se na cidade de Londrina, realizou “atividades marcantes na instalação do Partido Comunista no Paraná e em todos os seus setores" e ao fim do Estado Novo, com a intenção do partido em entrar na legalidade, "exonerou-se das funções na imprensa e começou a participar de Comitês Democráticos Populares, com a finalidade de preparar o povo em favor da legalidade do partido comunista".

Nos trechos finais do seu breve histórico, o relatório aponta que "esse elemento que sempre viveu em precária situação econômica, depois que começou a se integrar no movimento partidário, teve sempre desafogo financeiro", de maneira hipotética, o relatório sugere que a remuneração de Flavio Ribeiro se dava pelo partido e que "trata-se de uma pessoa inteligente e capaz, profundo conhecedor da filosofia marxista e dos métodos mais eficientes de propagação" ${ }^{\text {. }}$ A ação política de Flavio Ribeiro se faz presente desde abril de 1936, com sinais de suspeitas de “exercer atividades comunistas" naquele momento, até 1979, quando é anistiado ${ }^{17}$.

Angelo Maria Pattitucci, alfaiate, a partir do breve histórico de militância que a DOPS levantou acerca de sua atuação na cidade de Paranaguá, em março de 1940 é descrito como “comunista fervoroso". Pattitucci aparece como Secretário de Organização e Finanças do Comitê Municipal do PCB, na data de 19 de setembro de 1945. Ainda no mesmo ano, os dados informam que reuniões do partido foram realizadas dentro de sua casa, e que a estruturação de uma das células comunistas da cidade, chamada Leocádia Prestes, "'que sobre a orientação do fichado, foi mais um passo andado no caminho da Organização Política de que está o mesmo empenhado', essas foram as palavras de seus companheiros, na referida reunião". Também "conhecido como chefe dos

\footnotetext{
${ }^{15}$ GONÇALVES, Márcio Mauri Kieller. Elite Vermelha: Um perfil socioeconômico dos dirigentes estaduais do Partido Comunista Brasileiro no Paraná - 1945 - 1964. Dissertação (Mestrado em Sociologia). Curitiba: UFPR, 2004.

${ }^{16}$ DEAP/DOPS. Dossiê: Pasta Individual de Flavio Ribeiro. No: 1216. Topografia: 341. pp. 77-78.

${ }^{17}$ DEAP/DOPS. Ficha Individual de Flavio Ribeiro. No $: 34.480$.
} 
elementos comunistas, conforme informação do agente reservado de Paranaguá" em 31 de março de $1948^{18}$.

Desempenhou outros cargos no interior do partido, um desses cargos foi o de Secretário Político, aparecendo suas atividades através de cartas assinadas sob esta função, na data de 16 de março de 1946, cartas essas endereçadas a Walfrido S. de Oliveira, Secretário Político do Comitê Municipal de Curitiba, tratando de assuntos relacionados ao Comitê de Paranaguá. Alguns meses depois, em 14 de julho, "consta o nome do fichado em um abaixo assinado, junto a Assembleia Constituinte, em sinal de protesto sobre a vinda dos fascistas do exército polonês do General inglês Andrews" $" 19$.

Há indícios de suas atividades como comunista que remontam à década de 1930, seu nome está presente juntamente com outros, em relatório datado de 27 de maio de 1936, levantado por inspetores que se identificam como "8" e "10" da Delegacia Auxiliar. Neste relatório, Pattituci aparece como membro da Aliança Nacional Libertadora, ao lado de outras pessoas que também fazem parte da mesma organização ${ }^{20}$.

Contudo, o curioso das atividades de Pattituci é que "em julho de 1937, com o nome de Angelo Pacheco foi nomeado agente reservado desta D. O. P. S., prestando então interessantes informações de seus antigos companheiros. Até 1939 serviu a esta Delegacia”, mais adiante, no ano de 1945, nos deparamos com outra informação controversa em relação à Angelo Pattituci, onde seu trânsito de um extremo ao outro, ou seja, da Aliança Nacional Libertadora à agente reservado da Polícia Política, é observável quando sua ficha aponta que "assinou uma moção de apoio à União Democrática Nacional, tendo em 27 de julho do mesmo ano publicado na 'Gazeta do Povo' uma declaração na qual se desligava daquele partido 'por se achar perfeitamente integrado à linha política do Partido Comunista do Brasil, ao qual sempre pertenceu'"21. Márcio Mauri Kieller Gonçalves cita Angelo Pattituci como o dirigente do partido em Paranaguá nos anos quarenta, também apontando esta característica de agente infiltrado da repressão do governo Vargas ${ }^{22}$.

\footnotetext{
${ }^{18}$ DEAP/DOPS. Ficha Individual de Angelo Maria Pattituci. No: 30.754.

${ }^{19}$ DEAP/DOPS. Idem.

${ }^{20}$ DEAP/DOPS. Dossiê: Pasta Individual de Angelo Maria Pattituci. No: 0257. Topografia: . p. 15.

${ }^{21}$ DEAP/DOPS. Ficha Individual de Angelo Maria Pattituci. No: 30.754.

${ }^{22}$ GONÇALVES, Márcio Mauri Kieller. Op. cit. p. 87.
} 


\section{A TRAJETÓRIA DE UM SAPATEIRO: ENTRE LEITURAS E MILITÂNCIA}

Chamava-se Antônio Araújo Rocha, conhecido por Antoninho sapateiro. Nascera em 1908, em Superagui, uma ilha do litoral do Paraná, povoada em sua maioria por pescadores. Viveu pouco tempo nesta ilha, ainda com dois anos de idade, seus pais mudaram-se para a Ilha da Cotinga, mais próxima da cidade de Paranaguá. Em seguida, cerca de dois anos após estarem morando na Ilha da Cotinga, seguiram moradia para a cidade de Paranaguá, no bairro da Costeira, um bairro muito próximo da região portuária e do centro, habitado por operários, portuários e pescadores. De origem humilde, vindo de família pobre, Antônio Araújo Rocha não concluiu seus estudos básicos, abandonando a escola pública ainda muito cedo, segundo ele próprio, ficou "até o meado do quarto ano, depois eu saî" 23 .

Seus pais, Arcelino Rocha e Presciliana Araújo Rocha, insistiram para que continuasse os seus estudos, porém, sua vontade de continuar foi cerceada por conflitos e brigas dentro do ambiente escolar, pois, "[...] havia uma divisão muito grande entre os alunos... briga, a gente brigava, né. Foi por causa dessa divisão que eu saí da escola, acabei brigando lá.... [...]”. Como parou de frequentar a escola, decidiu ir aprender o ofício de sapateiro. A partir de 1922, aproximadamente, Antônio Araújo Rocha iniciaria sua vida de trabalhador, dedicando-se à confecção e consertos de sapatos.

Para o jovem sapateiro, um mundo se abriria a partir da experiência que iria adquirir diante do ofício. Paciência, atenção, dedicação e solidão fariam parte do seu cotidiano nesse mundo do trabalho. E diante desse mundo do trabalho, outro ingrediente faria parte de sua vida, algo que o acompanharia para o resto de seus dias e que estava sendo desenvolvida, ainda nos tempos da escola primária, uma companhia silenciosa e falante, sempre à sua espera nas manhãs, tardes, noites e madrugadas, junto com um café quente e fresco ou a velha e boa pinga. Essa companhia seria a leitura, um instrumento poderoso e de grande importância para o sapateiro, àquilo que o faria pensar e agir, intervindo à sua maneira na sociedade em que viveu, mas que o transportou para outros lugares, através da imaginação.

Sua leitura de si, através da memória, permite-nos uma noção de como era sua relação com o mundo das letras, “[...] por intuição, sempre gostei de ler, desde guri... Sempre gostei de revista, livro, tudo. Fui me dedicando a leitura... Foi indo, foi indo. Eu leio bastante, eu leio bastante, eu leio

${ }^{23}$ Transcrição do depoimento concedido ao Centro de Memória Sindical do Paraná, em Curitiba, 1988. p. 03. 
muito [...]"24. Em outro momento, comenta que seu gosto pela leitura teve incentivo por parte de um antigo professor, nos tempos de escola, chamado Manoel Viana ${ }^{25}$.

Nesse período, após iniciar suas atividades como um artífice sapateiro, na década de 1920, Antônio Rocha estava amadurecendo as suas ferramentas de leitura, ainda não chegara às leituras mais densas, diretamente direcionadas para as reflexões do pensamento político - refiro-me aos livros e revistas de conteúdo marxista, ligados ao Partido Comunista, por exemplo. No entanto, entraria em contato com assuntos que eram de seu interesse e que, de certa maneira, o preparariam para o que viria. Nesse sentido, podemos compreender esta fase de sua vida como uma conjuntura em que se gestaria o militante político que viria a ser alguns anos mais tarde.

Suas leituras, durante os anos vinte - bem como em todas as décadas adiante -, são rodeadas por assuntos diversos, mas que possuem, de certa forma, um fio condutor em comum. Este fio condutor pode ser identificado com o possível gosto pela atividade de imaginar, pelo sentimento de curiosidade e pela necessidade do conhecimento. O interesse pelo cinema e as publicações em torno desta arte, materializado nos indícios que emergem de seu acervo e de sua experiência como leitor, sugerem que nesse momento sua formação como leitor autodidata se desenvolve através do que estava sendo debatido nos círculos especialistas, dedicados às análises das obras fílmicas. Haveria certa circularidade da cultura do cinema, apropriada e reelaborada por ele.

A revista Cinearte é uma das referências que fazem parte desse universo de leitura, experimentada por Antônio Rocha neste primeiro estágio, lembrada por ele como uma revista do

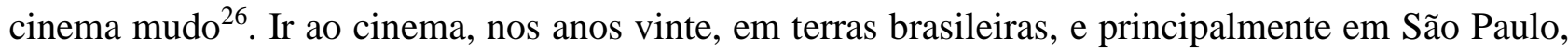
significava dividir a companhia de um filme com muitos trabalhadores das camadas populares, curiosos pelas produções cinematográficas que chegavam aos trópicos. Porém, os cinemas eram restritos às grandes cidades brasileiras, dificultando o acesso para quem quisesse deitar os olhos em uma tela. Para muitos, a única maneira de aproximar-se dos filmes era manter contato com as publicações que se dedicavam aos assuntos cinematográficos ${ }^{27}$.

\footnotetext{
${ }^{24}$ Idem, p. 03.

${ }^{25}$ Revista Outras Palavras, ano I, nº 0utubro de 1978. "Um sapateiro e o mundo da literatura", entrevista concedida a Fernando Nogueira e Reinoldo Atem.

${ }^{26}$ No processo de catalogação de seu acervo de livros e revistas, a revista Cinearte não estava presente em suas estantes. É muito possível que tenha se perdido nos anos que se passaram.

${ }^{27}$ A historiadora Sheila Schvarzman traz apontamentos interessantes a respeito do cinema dos anos 1920 em São Paulo, oferecendo questões que podem ser pensadas no contexto do Paraná, na mesma época. Ver: SCHVARZMAN, Sheila. Ir ao cinema em São Paulo nos anos 20. Revista Brasileira de História. São Paulo, v. 25, nº49, p. 153-174 - 2005. Nesse sentido, apontamos a necessidade de estudos a respeito do cinema e de sua recepção no Paraná, especialmente em Curitiba e nas cidades próximas, como em Paranaguá, principalmente na relação entre Cinema e trabalhadores.
} 
Quantos trabalhadores manifestaram suas curiosidades e vontades de aprofundamento no conhecimento a respeito do cinema e não puderam, por ter o acesso limitado? Quantos desejaram ler sobre o assunto e não conseguiram, pois não sabiam ler? No momento, não temos como saber a quantidade de trabalhadores que sentiram o encantamento pelo cinema, entretanto, certamente, este número de pessoas interessadas foi elevado, e por causas diversas, não tiveram oportunidades em seguir seus desejos e vontades, em alimentar suas paixões e sentimentos.

O gosto pelo cinema acompanha Antônio Rocha desde cedo em sua vida, é possível que o contato com os filmes, em algum momento de sua infância ou adolescência, o tenha levado para uma vida de leituras. A respeito do assunto, o sapateiro expõe para a revista curitibana Outras Palavras, em 1978, que "o cinema o tem fascinado e foi o que o iniciou no amor à cultura, antes mesmo das letras. Leu Sadoul, Pudovkin"28.

Em seu acervo de $\operatorname{livros}^{29}$, localizam-se as seguintes referências, que nos oferecem as possibilidades de leitura que havia disponível acerca da temática cinematográfica: Vsevolod Pudovkin, $O$ ator no cinema, sem data de publicação; Carlos Ortiz, Romance do gato preto: História breve do cinema, sem data de publicação; Georges Sadoul aparece com três livros, $O$ cinema: Sua arte, sua técnica, sua economia, com data de 1951, A vida de Carlitos: Charles Spencer Chaplin, seus filmes e sua época, de 1952 e História do cinema mundial: Das origens a nossos dias, publicado em 1963; Ismail Xavier, D. W. Griffith: O nascimento de um cinema, de 1984; Salvyano Cavalcanti de Paiva, O gangster no cinema, sem data de publicação; Alberto Cavalcanti, Filme e Realidade, sem data de publicação; e por fim, Bela Balazs, Estética do Filme, de 1958.

As diferenças entre as datas de publicação - e a ausência de algumas - , permitem a interpretação de que Antônio Rocha continuou alimentando o interesse pelo cinema no decorrer do tempo, no entanto, não é possível um aprofundamento a respeito do modo como leu esses livros, pois não é presente na documentação - nos livros, na forma de anotações - informações que nos levem para a compreensão do sapateiro acerca da leitura que realizou. Contudo, o contato com tais autores revelam que Antônio Rocha estava, pelo menos, sabendo do que cada um escreveu, caso a leitura dos livros tenha se realizado.

Além do interesse pelo cinema, dedicava-se à leitura de romances, que o acompanhariam por longos anos. Porém, o seu início na atividade de sapateiro caracteriza-se, para além da leitura

\footnotetext{
${ }^{28}$ Revista Outras Palavras, ano I, nº 0utubro de 1978. "Um sapateiro e o mundo da literatura", entrevista concedida a Fernando Nogueira e Reinoldo Atem.

${ }^{29}$ Em anexo, segue disponível a lista de todos os livros e revistas presentes na biblioteca de Antônio Araújo Rocha.
} 
ligada a assuntos do cinema e de romances - geralmente de folhetins, entre as décadas de vinte e trinta -, como um período de aprendizado autodidata nos temas da gramática da língua portuguesa e da administração de finanças, bem como da matemática. Como abandonou a escola, suas necessidades de conhecimento aumentaram.

Com uma sapataria para administrar, podemos imaginar que havia a necessidade de desenvolver as suas capacidades de escrita, leitura e administração dos materiais de trabalho, principalmente na compra de couro, cola, graxa de sapato e ferramentas que o auxiliariam no cotidiano da sapataria, de forma que o amadurecimento como leitor se deu em compasso com o seu amadurecimento como sapateiro.

A atividade rotineiramente isolada do artífice contribuiu, ora consciente, ora inconscientemente, para que forjasse o leitor que se tornou. Como Eric Hobsbawm e Joan Scott comentam, aquele ambiente de trabalho solitário, característico de muitos sapateiros, durante o século XIX europeu, também se manifestou à sua maneira neste caso, somando para que Antônio Rocha intercalasse o seu trabalho com leituras diversas, aprimorando o seu método de leitura com o passar dos anos ${ }^{30}$.

Para poder compreender como o roteiro de leituras de Antônio Rocha estava se constituindo, é necessário apresentar os títulos que provavelmente serviram de aprimoramento ao seu conhecimento. Sugerimos denominar esse conhecimento como utilitário e/ou prático, para as tarefas cotidianas do trabalho na sapataria, lembrando que esse acúmulo de leituras não se dissocia do aprendizado autônomo de outras leituras - romances, em especial.

Entre os anos vinte e trinta, as incidências de livros voltados para o aprendizado da língua portuguesa caracterizam-se com alguns títulos do autor Carlos Goés ${ }^{31}$. Com data de publicação de 1921, o Diccionario de Raizes e Cognatos da Lingua Portugueza aparece com a assinatura de Antônio Rocha do dia 5 de agosto de 1932. Outro livro presente é a segunda edição de Syntaxe da Construcção: Inclusive collocação dos pronomes pessoaes obliquos atonos, publicado em 1936, mas, novamente assinado pelo sapateiro, com data de 5 de agosto de 1937.

\footnotetext{
${ }^{30}$ HOBSBAWM, Eric; SCOTT, Joan. Sapateiros Politizados. In: HOBSBAWM, Eric. Mundos do Trabalho: Novos estudos sobre História Operária. $5^{\mathrm{a}}$ ed. Trad. Waldea Barcellos e Sandra Bedran. Rio de Janeiro: Paz e Terra, 2000. p. 158.

${ }^{31}$ Carlos Goés foi um proeminente dicionarista, dramaturgo, poeta e gramático brasileiro. Nasceu em 1881, tendo data de sua morte o ano de 1934. No seu Diccionario de Galicismos, publicado em 1921, seu objetivo era o de excluir a proliferação da língua francesa do vocabulário português, observando que, entre as décadas de vinte e trinta do século XX, havia um número excessivo de palavras francesas no uso cotidiano do português. Ver: SCHMITZ, John Robert. Palavras estrangeiras e a língua portuguesa: Invasão cultural ou desenvolvimento técnico-científico? Calibán, Revista de Cultura. Recife, maio 2000, pgs. 42-46 ID. 92148. Acesso em: 20/01/2014. Disponível em: http://www.unicamp.br/iel/site/docentes/John/lingport.html
} 
Há, também, o Diccionário de Affixos e Desinencias e o Pontos de Língua Pátria, ambos publicados em 1930. Em sua terceira edição, o livro Ortographia, Dictado, Pontuação, Crase, de 1935 está presente, bem como o Gramática Expositiva Primária, sexta edição, de 1939. Por ter grafado as datas nas folhas de rosto, vemos o mecanismo - bem conhecido entre muitos leitores - de registrar o momento de aquisição dos livros, assim, localizam-se no tempo o seu interesse por tais leituras, ou seja, aquilo que estava circulando em seu repertório de conhecimento.

A busca por tais temas refletem o abandono da escola e o desejo de educar-se por conta própria. Outros livros com a mesma temática também são presentes, como o Lingua Vernacula: Grammatica e Anthologia, publicado em 1935, de José de Sá Nunes; Aprende tu mesmo a redigir: Breves lições de redação em prosa, para uso dos alunos da $4^{a}$ e $5^{a}$ série, e da mocidade em geral, de 1937, autoria de Estevão Cruz; Escrever certo, de 1938, autoria de Aires da Mata Machado Filho, com assinatura do sapateiro e o provável dia da aquisição do livro, grafado em 14 de agosto de 1938; Iniciação Linguistica, de 1929, escrito por F. V. Lorenz; por fim, a sexta edição de Grammatica Historica, sendo o autor Eduardo Carlos Teixeira, publicado em 1929, mas, adquirido por Antônio Rocha em 25 de agosto de 1934.

Ao passo em que esses tipos de livros surgem no acervo de Antônio Rocha, verificam-se publicações direcionadas para o desenvolver do conhecimento administrativo e contábil, provavelmente a ser pensado junto às atividades como sapateiro, na organização das contas da sapataria e dos possíveis lucros e gastos. A observação dos títulos oferece os rastros da preocupação com os assuntos relacionados, significando um importante indício para entender o cotidiano de leituras ao qual Antônio Rocha estava formando para si.

Os títulos que circundam essa temática são os seguintes: Analyse logica no curso primário pelo processo dos diagramas, autoria de José Scaramelli, publicado em 1927, com assinatura do sapateiro datada em $1^{\circ}$ de abril de 1936; Noções de Commercio e Escripturação Mercantil, escrito por Horacio Berlink, publicado em 1921 e com um pequeno aviso escrito na folha de rosto, onde é informado por Antônio Rocha que o livro foi comprado em junho de 1934; Vida Efficiente ${ }^{32}$, livro escrito por Edward Earle Purinton, sem data de publicação, mas, assinado e datado em 2 de fevereiro de 1932; Contabilidade: Noções preliminares, autoria de Francisco D’Auria, publicado em 1939; Matemática fácil e atraente: Metodologia da matemática na escola primária, sem autor, publicado em 1938, assinado e datado por Antônio Rocha em 9 de julho do mesmo ano; e, por

\footnotetext{
${ }^{32}$ Este livro pode ser encarado como dentro dos dois grupos de leituras até aqui apresentados, isto é, das leituras de aprendizado gramatical e das leituras voltadas para as atividades comerciais, pois apresenta em seu índice questões ligadas para a constituição de pessoas eficientes em vários setores da vida, como, por exemplo: o trabalho, o estudo, a alimentação, o lar, etc. Possivelmente o significado da palavra "eficiência", nessas áreas, despertou a atenção de Antônio Rocha para que este livro formasse parte de seu acervo.
} 
último, a sétima edição do Método Prático de Análise Lógica, escrito por Antenor Nascentes e publicado em 1930.

Alguns livros não são possíveis de se fazer identificar o momento da aquisição, mas mesmo assim, interessa mencionar a relação de possuir tais livros em seu acervo, podendo neles estarem as respostas que Antônio Rocha procurava, instigando o interesse em aprender o mínimo ou o máximo possível, para a sua educação autodidata e para sua formação como trabalhador, na hora de realizar e resolver as questões ligadas ao comércio.

Ao mesmo tempo em que se encontram os livros relacionados ao aprendizado da gramática e ao conhecimento das atividades comerciais, em pelo menos no atravessar de uma década para a outra, ou seja, dos anos vinte para os anos trinta, Antônio Rocha mantém um hábito que é possível observar, como citado anteriormente, ligado à leitura de romances que, segundo ele, eram vendidos de porta em porta, bem como revistas e almanaques, livros de psicologia e literatura brasileira e europeia dos séculos XIX e XX. Podemos rastrear essas leituras, e em alguns casos, obter maior aproximação do que chamou a atenção do leitor em formação, através de grifados e anotações nos livros. Como o número de livros é expressivamente alto, optamos por apresentar alguns e pensar a partir deles ${ }^{33}$

Esse período de leituras, identificado posteriormente por Antônio Rocha como um período de leituras de prazer, é interessante pela heterogeneidade de temas que se forma em seu acervo, podemos entendê-las como leituras diletantes, realizadas pelo prazer da leitura, para passar o tempo, apreciando as linguagens diversas com que eram escritas e, talvez, o estimular da imaginação e o enriquecimento do vocabulário, como ele mesmo afirma ${ }^{34}$. É importante destacar que, dada a dimensão de seu acervo, é possível que não tenha lido tudo o que adquiriu.

Publicado em 1929, em sua quinta edição, o livro Pequena História do Brasil: Para uso das escolas primarias, escrito por Mario da Veiga Cabral, constitui esse aglomerado de assuntos diversos que irão aparecer ao longo das décadas, no acervo de Antônio Rocha. Outro livro de história é presente com o exemplar do historiador francês Ernest Renan, Os evangelhos e a segunda geração christã, de 1929; o Romanceiro, terceira edição, escrito por Coelho Netto e publicado em 1924, mas com assinatura e data de 10 de junho de 1937; há um livro de Ruy Barbosa, de 1923, intitulado como Orações do Apostolado: Marques de Pombal, Lyceu de Artes e Officios, Jornal do Commercio, Ensaio sobre Swift.

\footnotetext{
${ }^{33}$ A totalidade do acervo de Antônio Araújo Rocha encontra-se listada em anexo em minha dissertação de mestrado, para fins de consulta. Está disponível na Biblioteca Digital da UFPR.

34 A heterogeneidade do acervo que constitui a biblioteca de Antônio Rocha é uma característica que se tornará constante até o fim de sua vida, quando para de alimentar de suas estantes com livros, revistas e almanaques.
} 
O escritor espanhol Vicente Blasco Ibañez ${ }^{35}$ marca presença nas estantes de Antônio Rocha, com o livro Os quatro cavaleiros do Apocalipse, segunda edição, publicado em 1924 na cidade de Lisboa, e com assinatura e data do sapateiro em 8 de novembro de 1937. Este livro oferece grifos em vários trechos, e que podem nos fornecer detalhes potencialmente reveladores para compreender a dimensão do tipo de leitura realizada, atraindo o olhar de Antônio Rocha para um conjunto de ideias mais amplas e que estavam sendo muito discutidas na conjuntura internacional, no momento em que adquire o livro.

A partir dos grifos deixados por Antônio Rocha, aproximamo-nos de seu olhar diante do texto; os conteúdos dos trechos destacados parecem evidenciar uma identificação com os personagens oprimidos, por um lado, e as características autoritárias e opressoras de conflitos entre classes, por outro. Considerando a leitura que faz de si mesmo, lembrando-se de seu contexto nos anos quarenta, Antônio Rocha irá comentar que suas leituras da realidade passaram a ter outros sentidos após entrar em contato com o Partido Comunista, porém, muito provavelmente esta percepção poderia estar sendo gestada anos antes, do seu próprio modo, sem intervenções exteriores, sem seguir as orientações do partido do que deveria ser lido, e principalmente, da forma como ler ${ }^{36}$.

Pensamos ser interessante direcionar a atenção para a maneira como as frases estão articuladas, oferecendo situações e ideias para o leitor trabalhar a imaginação, ou trazendo respostas para os seus anseios, estimulando os sentimentos de identidade em relação a conjuntos argumentativos. $\mathrm{O}$ trecho a seguir refere-se às camadas mais pobres das sociedades modernas:

[...] A filosofia da democracia moderna é um cristianismo laico. Nós, os socialistas, amamos os humildes, os necessitados, os fracos. Defendemos o seu direito à vida e ao bem estar, como os grandes exaltados da religião, que em todos os infelizes e deserdados viram irmãos. Exigimos o respeito pelo pobre em nome da justiça; os outros pedem-no em nome da piedade. Isto nos separa unicamente. Mas uns e outros diligenciamos porque os homens se ponham de acordo para uma vida melhor; que o forte se sacrifique pelo fraco, o poderoso pelo humilde, e que o mundo se reja pela fraternidade, procurando a maior igualdade possível.

[...] A civilização é o afinamento do espírito, o respeito do semelhante, a tolerância pela opinião alheia, a suavidade dos costumes ${ }^{37}$.

\footnotetext{
35 Escritor espanhol que dedicou-se a política, a literatura e ao jornalismo. Nasceu em 1867 e morreu em 1928. Caracterizado como entusiasta e defensor dos ideais republicanos, oponde-se às monarquias.

${ }^{36}$ Mais adiante, iremos comentar a respeito da transição de leituras feita por Antônio Rocha, reconhecidas por ele em dois momentos, feitas de um modo diferente antes da entrada no Partido Comunista do Brasil e o significado das leituras, que passaram a serem realizadas após o ingresso no PCB.
}

${ }^{37}$ IBAÑEZ, Vicente Blasco. Os quatro cavaleiros do apocalipse. $2^{\mathrm{a}} \mathrm{ed}$. Trad. Raul Proença. Lisboa: Livraria Peninsular Editora, 1924. Respectivamente, a primeira citação encontra-se grifada na página 133 e a segunda na página 136. 
Em comum, os dois trechos expõem a necessidade da compreensão do outro e de suas diferenças, tornando viável a participação política dos mais pobres. Seria possível Antônio Rocha ter manifestado alguma empatia com esses trechos? Acreditamos que sim, principalmente, para o processo de formação como militante político. A própria orientação obreirista do PCB, durante os anos trinta, ofereceria tais condições de interpretação dos ideais revolucionários, identificando na figura do pobre, o potencial transformador da sociedade, vindo da classe trabalhadora.

Por outro lado, o contato e a identificação, com os mais pobres e o sofrimento que estes passam remetem à outra hipótese de Hobsbawm e Scott, a respeito da inclinação para o radicalismo político que os sapateiros teriam forjado. Segundo o próprio sapateiro, expõe que também passou por sofrimentos nos tempos de infância, entre 1910 e 1920, destacando que

minha família era muito pobre, de trabalhador, de operário, né. A vida é muito difícil naquele tempo, como hoje, né, mais difícil ainda. Apesar de todas essas dificuldades, a gente vai crescendo, vai vivendo, a vida de trabalhador é assim, né, passa fome, sofre, frio $^{38}$.

Pode ser que certo ressentimento, unido à empatia diante de leituras que o motivassem a pensar acerca dos problemas sociais - fome, principalmente -, contribuiriam para esse caldeirão de experiências reais adquiridas e imaginárias, formando o sapateiro-leitor-militante.

A partir deste ponto, pensamos ser necessário realizar um recorte no acervo de Antônio Rocha e procurar entender como se constitui um repertório de leituras voltadas para os problemas sociais, especificamente, partindo do que ele compreende como algumas leituras que o fizeram pensar nessas questões. Entre finais dos anos vinte e durante a década de trinta, houve uma mudança na compreensão de leitura e do significado atribuído a essa atividade pelo sapateiro, podemos refletir que o processo de amadurecimento estava começando a consolidar-se.

É nesse contexto, alguns anos antes de sua entrada no PCB, que essa modificação na leitura se faz, de forma lenta e que, após o ingresso no partido, seria interpretada de outra maneira, como mencionado anteriormente. Anos mais tarde, em seu depoimento, comenta sobre o seu entendimento acerca do que significa a leitura para si. É muito interessante observar como desenvolve suas ideias:

[...] Daqui um dia, você vai selecionar a leitura, você vai começar a compreender porque você está lendo o que você gosta de ler... Passando do prazer para a realidade. Passa a compreender que a leitura é uma necessidade na vida, tanto quanto o pão, é uma necessidade tanto quanto comer pão, né... Respirar o ar... Hoje, eu entendo assim.

Aí passei a ler outros autores. Por exemplo... Humberto de Campos, que me levou a ter toda a literatura de Humberto de Campos... Cronista, poeta, jornalista. É... e também, aquele

\footnotetext{
${ }^{38}$ Transcrição do depoimento concedido ao Centro de Memória Sindical do Paraná, em Curitiba, 1988. p. 02.
} 
outro...o francês Alexandre Dumas, Balzac, esses estrangeiro, né. Eu li muito deles também, né. Aquele... Lima Barreto, conheço toda a obra de Lima Barreto... Machado de Assis, José de Alencar... Mais outros, mas, esses que eu me prendi mais foi José de Alencar, Lima Barreto e Euclides da Cunha, né... Principalmente, Euclides da Cunha, o livro "Os Sertões".

Naquele livro que eu fui saber que havia uma luta nesse país contra o latifúndio. Eu tava pensando entrar dizendo que era o latifúndio. Ali, o que que tá acontecendo? É uma batalha muito grande contra o latifúndio nesse país. E, Antonio Conselheiro - comandante da luta , esmagaram com ele.. esmagaram... três vezes, na quarta investida, esmagaram com... esqueci o nome... do lugar que ele travou essa batalha, né... Canudos! ${ }^{39}$

Antônio Rocha divide sua vida de leituras em dois momentos, uma voltada para as leituras que ele julga serem caracterizadas como de prazer e as que estão no campo da realidade, provavelmente serem estas leituras as que compreendeu como questionadoras de sua realidade e que lhe ofereceram as ferramentas para criticar a organização do Partido Comunista em 1947, como demonstrado no capítulo anterior. O interessante aqui é que as leituras prazerosas formaram a capacidade de interpretação do sapateiro, de modo que, quando entrou em contato com as leituras da realidade, desenvolveu diferenciações no campo da leitura, selecionando as leituras potencialmente transformadoras de seu próprio mundo.

Em uma de suas anotações, vemos o seu interesse particular pelo livro de Euclides da Cunha, onde escreveu um trecho do capítulo seis, chamado Canudos não se rendeu, expondo o seguinte: "Canudos não se rendeu. Expugnado palmo à palmo, na precisão integral do termo, caiu no dia 5, ao entardecer, quando caíram os seus últimos defensores, que todos morreram. Eram quatro apenas: um velho, dois homens feitos e uma criança, na frente dos quais rugiam raivosamente cinco mil soldados" $"$.

A citação está no livro publicado em 1940, este sendo a décima quinta edição. A anotação, por sua vez, não é desse período, mas de no mínimo vinte anos depois, pois está escrita atrás de uma carta destinada a Antônio Rocha, sendo o remetente um de seus irmãos, com data de 14 de dezembro de 1960. Mesmo a anotação ter sido escrita, provavelmente, nesta data, não podemos descartar o interesse do sapateiro com esse trecho, que pode nos revelar o seu olhar para o tema da resistência, diante da opressão, num momento em que já atua politicamente, em nome do PCB, possuindo uma leitura diferente - mas que possui as suas continuidades de temas - da que estamos refletindo.

\footnotetext{
${ }^{39}$ Transcrição do depoimento concedido ao Centro de Memória Sindical do Paraná, em Curitiba, 1988. p. 3 e 4.

${ }^{40}$ Anotação atrás de correspondência destinada a Antônio Araújo Rocha, em posse de sua família, na cidade de Paranaguá. Trecho presente em: CUNHA, Euclides da. Os sertões. 15 ${ }^{\mathrm{a}}$ ed. Rio de Janeiro: Livraria Francisco Alves, 1940.
} 
Assim, é possível afirmar que essa mudança de leituras se deu, aproximadamente, a partir de 1934/1937, quando os livros de Humberto de Campos começam a aparecer em suas estantes. O mesmo acontece com Balzac, Alexandre Dumas, Euclides da Cunha, José de Alencar e Machado Assis - este último, aparecendo na sua biblioteca nos anos cinquenta, mas que está anos antes no seu acervo, biografado por outros autores. Muitos outros aparecem em suas estantes, como George Bernard Shaw, Emile Zola, Edgar Allan Poe, Mark Twain, Charles Dickens, Jack London, Leon Tolstoi, Michel Zevaco, John Steinback, Karl May, José Lins do Rego, Nikolai Gogol, Arthur Conan Doyle, entre outros ${ }^{41}$.

Com tal repertório de conhecimento, Rocha iria seguir para o Partido Comunista do Brasil. No entanto, em documento de 1936, emerge detido como preso político, juntamente com outras setenta e cinco pessoas, também na condição de presos políticos, na "Casa de detenção, annexa a Penitenciaria do Estado", preso entre 30 de novembro de 1935 a 05 de dezembro do mesmo ano ${ }^{42}$. Em seu depoimento, confirma esta informação,

[...] Em trinta e quatro, a gente a foi preso, né, fui preso lá. Fui preso uma vez também, me mandaram pra cá, pra Curitiba, né, vim pra cá, esses tempos vendiam bebida no trem, né, vendiam bebida no trem, e daí o polícia veio me trazendo, aí o polícia, 'quer beber alguma coisa?' Quando cheguei em Curitiba, cheguei bem. Aqui fiquei preso no DOPS aí, um dia, dois dias, essa data eu não lembro ${ }^{43}$.

Percebemos que há um erro de datação do ocorrido, como o depoimento foi dado na década de oitenta, é provável que a memória o traia nesses detalhes. Porém, ter sido detido como preso político no final de novembro de 1935 é um acontecimento potencialmente revelador, não apenas pelo fato de que a insurreição comunista tivesse ocorrido dias antes de sua prisão, no dia 25 de novembro, na cidade de Natal, no estado do Rio Grande do Norte, mas, pelo motivo de que a Aliança Nacional Libertadora tenha sido fundada meses antes, no mês de março.

Assim, podemos imaginar que Rocha foi detido por ter ligações com a ANL, como membro-militante, ou por manifestar ideias próximas às propostas de esquerda que eram veiculadas em sua conjuntura. Sua ligação ou não com a ANL não é possível de esclarecer, contudo, a ação de

\footnotetext{
${ }^{41}$ Lima Barreto e Michel Zevaco, por exemplo, foram ligados ao anarquismo. Mesmo em dois países diferentes, - o primeiro estando no Brasil e o segundo na França - , buscavam intervir na sociedade através de seus escritos e, de maneiras distintas, atuando politicamente. A trajetória de Michel Zevaco é interessante, pois, esteve envolvido no caso Dreyfuss, em fins do século XIX.
}

${ }^{42}$ DEAP/DOPS. Pasta Temática No 1468a. Topografia: 174. p. 174.

${ }^{43}$ Transcrição do depoimento concedido ao Centro de Memória Sindical do Paraná, em Curitiba, 1988. p. 20. 
ter sido colocado em detenção elucida-nos que representava uma ameaça à ordem, na percepção do Estado.

\section{CONSIDERAÇÕES FINAIS}

Antes de oficializar a sua entrada ao PCB, a percepção de leitura de Rocha já estava sofrendo alterações significativas, direcionando o seu olhar para reflexões literárias que problematizavam questões amplas na sociedade, como a fome, miséria, sofrimento diante da exploração e da opressão. Estar diante do partido o colocaria em contato com outra agenda de leituras, ao mesmo tempo próximas e distantes das que estava habituado a ler.

Esse contexto de pré-transição para o PCB caracteriza-se como um momento particular em sua trajetória, pois, segundo ele, "daí pra cá eu fui lendo, fui entrando em contato com outras leituras, com o Partido Comunista. Antes de eu entrar em contato com o Partido Comunista, no fim da Guerra de 1946, né". ${ }^{4}$ Isto significa ser um ponto de referência, podendo estabelecer comparações entre as de prazer e as da realidade.

Ao entrar no partido, observamos uma cisão, particularmente, podemos considerar uma reorganização mental da compreensão de mundo que é oferecida ao sapateiro, quando adere ao partido, muito próximo do que Jorge Ferreira argumenta sobre a entrada de muitos, no mesmo período, no PCB, refletindo que a entrada no partido e sua iniciação nas práticas que envolvem para ser um comunista efetivo, possui o significado de entrar em contato com mitos fundadores, que fundaram realidades, aproximando-se e conhecendo segredos, mistérios que ele pouco imaginava ou sequer pensava a respeito.

Contudo, no caso de Antônio Rocha, observamos que antes de seu ingresso ao aparelho partidário, a gestação de uma compreensão crítica da realidade já se manifestava, a partir dos anos que passou lendo literaturas distintas entre si. Talvez, as experiências de leitura teriam oferecido ferramentas de interpretação próprias do sapateiro, um método singular, criado em seus próprios termos. Mesmo apresentando rupturas em sua vida, como a entrada para o PCB ter sido um marco no modo como compreendia as leituras que fez, é necessário problematizarmos que este sentido de coerência biográfica que é exposto em seus depoimentos não deve ser interpretado como totalmente estável, isto é, como se sua vida fosse um continuum, uma progressiva narrativa, isenta de descontinuidades.

${ }^{44}$ Transcrição do depoimento concedido ao Centro de Memória Sindical do Paraná, em Curitiba, 1988. p. 04. 
Deste modo, a ilusão biográfica que Pierre Bourdieu destaca é fundamental para estarmos cientes das persuasões que os depoimentos biográficos nos fazem sentir. Aquele mesmo sapateiromilitante, preocupado em estar em contato com diferentes literaturas e autores, mostrou-se um indivíduo comum, ao mesmo tempo próximo e distante de nós, com sentimentos, desejos e necessidades de sobrevivência material e intelectual. $O$ que procuramos foi entender que a militância comunista em Paranaguá, se formou tanto quanto foi formada, esteve presente em seu próprio fazer-se, como reflete Edward Thompson em seus estudos clássicos sobre a classe operária inglesa. A militância surge em momentos muito específicos, significativos e de extrema importância para quem a forja, isto é, para os próprios militantes.

Segundo nosso entendimento, Antônio Araújo Rocha formou militantes, como também foi formado, numa relação intersubjetiva; em contato com os seus clientes que o procuravam, em sua sapataria; debatendo com colegas do partido; nas inúmeras vezes que foi preso na condição de preso político; a partir das leituras que fez, dos mais variados temas e autores; do modo como buscou organizar a sua biblioteca, formada como ele, no processo histórico que o tornou possível e que agora sabemos um pouco de sua trajetória, dos seus passos, dos rastros e indícios colhidos e organizados para o desenvolvimento da pesquisa que apresentamos até aqui.

\section{REFERÊNCIAS}

BOURDIEU, Pierre. A ilusão biográfica. In: FERREIRA, Marieta de Moraes; AMADO, Janaina. (Org.). Usos e abusos da História Oral. Rio de Janeiro: FGV, 1996.

GONÇALVES, Márcio Mauri Kieller. Elite Vermelha: Um perfil socioeconômico dos dirigentes estaduais do Partido Comunista Brasileiro no Paraná - 1945 - 1964. Dissertação (Mestrado em Sociologia). Curitiba: UFPR, 2004.

HOBSBAWM, Eric; SCOTT, Joan. Sapateiros Politizados. In: HOBSBAWM, Eric. Mundos do Trabalho: Novos estudos sobre História Operária. $5^{a}$ ed. Trad. Waldea Barcellos e Sandra Bedran. Rio de Janeiro: Paz e Terra, 2000. p. 158.

SCHVARZMAN, Sheila. Ir ao cinema em São Paulo nos anos 20. Revista Brasileira de História. São Paulo, v. 25, nº49, p. 153-174 - 2005.

THOMPSON, Edward Palmer. A formação da classe operária inglesa: A árvore da liberdade. Trad. Denise Bottmann. Rio de Janeiro: Paz e Terra, 1987. 


\title{
A SHOEMAKER AND HIS LIBRARY: THE MAKING OF A COMMUNIST IN THE CITY OF PARANAGUÁ
}

\begin{abstract}
The purpose of this article is to discuss the process of forming the communist militancy in Paranaguá, Paraná coast, between 1935-1964. Our starting point is the trajectory of the shoemaker Antônio Rocha Araújo, militant of the Communist Party in Paranaguá, active both in the party's internal structure and in relations with city workers. We have analyzed the mobilizations of workers related to the communist militancy and their organizations, internal and external conflicts and their process of formation during the time frame that we have adopted. As a guide, the shoemaker Antonio Araújo Rocha is highlighted in this research as a key driver for the development of the study, presented here most prominently, now appearing as supporting the experiences and political practices of Paranaguá workers. We seek to understand their intellectual training, from his personal library and his activities as a communist activist with the main reference studies of Edward Palmer Thompson and his notion of the historical process. The research was conducted from documents collected by the Bureau of Political and Social Order - DOPS, located in the Public Archives of Paraná and the collection of the shoemaker Antonio Rocha Araújo books in possession of his family in Paranaguá.
\end{abstract}

Key-words: Communist militancy. Workers. History process. Paranaguá 